\title{
RESEARCH
}

Open Access

\section{Antibiotic prescriptions in Italian hospitalised children after serial point prevalence surveys (or pointless prevalence surveys): has anything actually changed over the years?}

Chiara Tersigni ${ }^{1,2,3^{*}}$, Carlotta Montagnani ${ }^{3}$, Patrizia D'Argenio ${ }^{4}$, Marzia Duse ${ }^{5}$, Susanna Esposito ${ }^{6}$, Yingfen Hsia', Mike Sharland ${ }^{1}$ and Luisa Galli ${ }^{3}$

\begin{abstract}
Background: Point prevalence surveys have been used in several studies to provide immediate and easily comparable information about antibiotic use and showed that about one third of hospitalised children had on ongoing antimicrobial prescription during their hospital admission. The aim of this study, as part of the Global Antimicrobial Resistance, Prescribing and Efficacy in Neonates and Children project, is to describe antimicrobial prescriptions among hospitalised children in four tertiary care hospitals in Italy to show if something has changed over the years.

Methods: Four tertiary care Italian's hospitals joined three Point Prevalence Surveys (PPSs) in three different period of the year. All children under 18 years of age with an ongoing antimicrobial prescription, admitted on the participating wards at 8 o'clock in the morning of the selecting day were enrolled.

Results: A total of 1412 patients (475 neonates and 937 children) were admitted in the days of three PPSs. Overall, among the total admitted patients, 565 patients (40\%) had an ongoing antimicrobial prescription in the days of the survey A total of 718 antibiotics were administered in the 485 admitted children and 133 in neonates. The most common indications for antibiotic therapy in children was Lower respiratory tract infections (244/718, 34\%), while in neonates were prophylaxis for medical problems (35/133, 26.3\%), newborn prophylaxis for newborn risk factors (29/ 133, 21.8\%) and prophylaxis for surgical disease (15/133, 11.3\%).
\end{abstract}

Conclusions: Based on our results, it appears that nothing has changed since the last PPS and that the quality improved targets, underlyined in previous studies, are always the same. Serial PPSs can be part of AMS strategies but they are not sufficient alone to produce changes in clinical practice.

Keywords: Antimicrobial stewardship, Children, Antimicrobials, Point prevalence surveys

\footnotetext{
* Correspondence: chia88.te@gmail.com

${ }^{1}$ Institute for Infection and Immunity, Paediatric Infectious Disease Research

Group, St. George's, University of London, London, England

${ }^{2}$ Post graduate school of Paediatrics, University of Florence, Florence, Italy

Full list of author information is available at the end of the article
}

(c) The Author(s). 2019 Open Access This article is distributed under the terms of the Creative Commons Attribution 4.0 International License (http://creativecommons.org/licenses/by/4.0/), which permits unrestricted use, distribution, and reproduction in any medium, provided you give appropriate credit to the original author(s) and the source, provide a link to the Creative Commons license, and indicate if changes were made. The Creative Commons Public Domain Dedication waiver (http://creativecommons.org/publicdomain/zero/1.0/) applies to the data made available in this article, unless otherwise stated. 


\section{Background}

According to the World Health Organization (WHO)'s statements, antimicrobial resistance (AMR) is one of the major contemporary threats to public health, both for epidemiological and economic reasons [1]. Several studies have demonstrated that AMR development is related to broad spectrum antimicrobial use and that the optimization of AM prescriptions is a key point of antimicrobial stewardship programs (ASPs) [2]. Repeated Point Prevalence Surveys (PPSs), conducted in several European and nonEuropean countries, demonstrate high broad spectrum antibiotic use in hospitals [3-6].

The aim of this study, as part of the Global Antimicrobial Resistance, Prescribing and Efficacy in Neonates and Children (GARPEC) project, was to compare antimicrobial prescriptions among hospitalised children in four tertiary care hospitals in Italy using the same methodology from previous pediatric PPS's, to investigate if previous PPS studies had led to any change in clinical prescribing practice.

\section{Methods}

The present study is part of the GARPEC, the global study that followed the European Antibiotic Resistance and Prescribing in European Children project (ARPEC) [3-6]. Three PPSs were conducted: the first one from May to June 2016, the second one from August to September 2016, and the last one from November to December 2016. Four tertiary care university Italian hospitals participated three PPSs. The methodology and data collection has been described elsewhere [3-8]. A comparison between the results of the present study and two other studies conducted in Italian institutions, with the same methodology, is reported in Table $1[4,5]$.

\section{Statistical analysis}

Statistical analysis was performed using SPSS (version 25.0, SPSS Inc., Chicago, IL). Metric data were tested for normal distribution. Results were expressed as mean (standard deviation, SD) or median (interquartile range, IR) as appropriate. Unpaired $t$ test and Mann-Whitney

Table 1 Comparison between the present study and previous PPS studies $(4,5)$

\begin{tabular}{|c|c|c|c|}
\hline & Ciofi Degli Atti et al. (4) & De Luca et al. (5) & Present study \\
\hline \multicolumn{4}{|l|}{ Overall } \\
\hline Year & June 2007 & October-December 2012 & February - December 2016 \\
\hline Number of PPSs & 1 & 1 & 3 \\
\hline Participating hospitals & 1 & 7 & 4 \\
\hline $\begin{array}{l}\text { Percentage of patients with an ongoing } \mathrm{AMs}^{* *} \\
\text { prescription }\end{array}$ & $43.9 \%$ & $38.9 \%$ & $40 \%$ \\
\hline Mean prescription/treated patient & 1.4 & 1.56 & 1.32 \\
\hline Combination therapy/treated patients & $43.8 \%$ & $41.3 \%$ & $41.9 \%$ \\
\hline AMs prescribed empirically & $51 \%$ & - & $72.6 \%$ \\
\hline \multicolumn{4}{|l|}{ AMs use in Neonates } \\
\hline Percentage of neonates receiving AMs & $--^{*}$ & $17.3 \%$ & $16.4 \%$ \\
\hline AMs used for prophylaxis & - & $62.8 \%$ & $59.4 \%$ \\
\hline AMs used for treatment & - & $37.2 \%$ & $40.6 \%$ \\
\hline Most common reason for treatment & - & Sepsis & Sepsis \\
\hline \multirow[t]{2}{*}{ Top two prescribed AMs } & - & Penicillins & Aminoglycosides \\
\hline & & Aminoglycosides & Ampicillin \\
\hline \multicolumn{4}{|l|}{ AMs use in Children } \\
\hline Percentage of children receiving AMs & - & $47 \%$ & $51.8 \%$ \\
\hline AMs used for prophylaxis & - & $35.5 \%$ & $21.3 \%$ \\
\hline AMs used for treatment & - & $64.4 \%$ & $78.7 \%$ \\
\hline Most common reason for treatment & - & LRTI & LRTI \\
\hline \multirow[t]{2}{*}{ Top two prescribed AMs } & $\begin{array}{l}\text { Third generation } \\
\text { cephalosporins }\end{array}$ & $\begin{array}{l}\text { Third generation } \\
\text { cephalosporins }\end{array}$ & $\begin{array}{l}\text { Third generation } \\
\text { cephalosporins }\end{array}$ \\
\hline & Penicilins plus enzyme inhibitor & Penicilins plus enzyme inhibitor & Penicilins plus enzyme inhibitor \\
\hline
\end{tabular}


tests were used to compare variables between groups. The $x$-square test and Fisher test were performed when appropriate.

\section{Results}

A total of 1412 patients (475 neonates and 937 children) were admitted on the days of three PPSs were carried out. Overall 565 patients (40\%; 565/1412) received at least one antibiotic prescription on the days of the survey, with $51.8 \%(485 / 937)$ and $16.4 \%(80 / 475)$ in children and neonates, respectively. Of these, $34.6 \%$ (114/ $329)$ in the first PPS, $39.8 \%(220 / 552)$ in the second PPS, and $47.3 \%(231 / 531)$ in the third PPS; $p<0.005)$.

\section{Antibiotics prescribed in children}

A total of 718 antibiotics (an average of 1.48 antibiotic prescriptions per children) were administered in children (aged >1 months) with no significant differences between three PPSs $(p=0.199)$. Excluding antibiotics prescribed for prophylaxis, a statistically significantly higher proportion of antibiotics were prescribed in the second and in the third PPS $(p<0.001)$. About $41.9 \%$ of children received a combination of two or more antibiotics. The two most common indications for antibiotic prescribing were lower respiratory tract infection (LRTI) (34\%) and prophylaxis for surgical disease and for medical problems (14.3 and 7.4\% respectively). Overall, the most commonly prescribed antibiotics were the third generation cephalosporins (26.3\%), penicillin with enzyme inhibitor (18.1\%), and aminoglycosides (12.7\%). The parenteral route of administration was used in 590/718 cases (82.2\%). Almost half of patients received antibiotics reported as community acquired infections (CAI) (50.8\%; 365/718 patients), and only $24.9 \%$ (179/718 patients) as hospital acquired infections (HAI), and 22.1\% (159/718 patients) as prophylaxis. In the cases of antibiotics administered for treatment (560/718, 78\%), only $27.4 \%(154 / 560)$ of antibiotics were prescribed targeted treatment with pathogen and antimicrobial susceptibility test confirmed.

\section{Antibiotics prescribed in neonates}

Overall, 16\% (80/475) neonates received at least one antibiotic in the days when PPSs were carried out. Overall, 80 neonates received at least one antibiotics in the days of three PPSs were carried out. Neonates with reported underlying conditions were more likely to receive antibiotic for treatment compare with those without underlying condition during the surveys $(77.5 \%$ vs $22.5 \%, p<0.001)$. Prematurity was the most common reported underlying conditions in our study population (32.5\%; 25/80 patients). Regarding antibiotic prescription, a total of 133 antibiotics were administered (an average of 1.66 antibiotic prescriptions per neonate).
The most commonly prescribed antibiotic, alone or in combination, was ampicillin or ampicillin and enzyme inhibitor (27.8\%) followed by gentamycin (18.8\%).

When the indication for antibiotic use was reported (127/133), antibiotics were administered for treating HAIs in $21.3 \%$ (27/127), for CAIs in the $15.7 \%(20 / 127)$ and for prophylaxis in 63\% (80/127). The parenteral route of administration was preferred in 128/133 cases (96.2\%). The most common reasons for antibiotic treatment in neonates were prophylaxis for medical problems (26.3\%), newborn prophylaxis for neonatal risk factors (21.8\%), prophylaxis for surgical disease $(11.3 \%)$, sepsis (11.3\%), treatment for surgical disease (10.5\%) and LRTI (9\%). The two most commonly prescribed antibiotics for medical prophylaxis were (alone or in combination) gentamycin $(9 / 35,25.7 \%)$ and ampicillin $(8 / 35,22.8 \%)$.

\section{Comparison with previous studies}

Two other studies, using the PPSs methodology have been published in the literature in 2007 and in 2012, respectively $(4,5)$. The percentage of patients with an antibiotic prescription, the number of antibiotics/treated patients, the percentage of antibiotics prescribed empirically and the characteristics of antibiotic use in children and neonates are reported in Table 1.

\section{Discussion}

The present study provides an estimate of antibiotic use in children and neonates in four tertiary care Italian hospitals, in three different seasons, using a standardised PPS methodology. About $40 \%$ of admitted patients received at least one antibiotic during their hospital stay; however, when new-borns are excluded, this percentage increases to more than $50 \%$. These data are concerningly, very similar to the previous PPS studies conducted in 2007 and in 2012 in Italian tertiary care hospitals (Table 1) [3-9]. The three PPSs reported in the present study, conducted about nine and seven years after the previous ones, respectively, did not reveal any reduction in overall AMs use. A number of specific quality improvement targets, identified as key points in ASPs, have been developed [1$3]$. The most commonly prescribed remained antibiotics were third generation cephalosporins (prescribed as first choice in LRTIs, skin and soft tissue infections and joint and bone infections) and penicillin with enzyme inhibitor and aminoglycosides. There remained an extensive use of antibiotics for prophylaxis, both for medical and surgical reasons, which is not supported by available guidelines [10]. There was very high rates of prescribing for prophylaxis in neonates (60.1\%). However, even though the neonatal population with risk factors (i.e. prematury) can be considered particulary vulnerable since invasive procedures 
are often necessary and because of the presence of an immature immune system, the huge use of antibiotics for prophylaxis cannot be considered evidence-based $[8,9,11]$.

\section{Conclusions}

PPS is an easy method to perform and monitor antibiotic use, with the main aim of raising awareness of the rationale of antibiotic prescriptions in the paediatric population. However, our study showed that PPSs by themselves are not sufficient to produce any changes in the clinical practice if they are not sustained by ASPs. Based on the present study, it appears that nothing has changed since the last PPSs $[4,5]$ and that the quality improvement targets, underlined in previous studies, are always the same. More attention should also be focused on whether this has been noted in other studies. It is unclear why there has been limited evidence of improvement in the quality of prescribing. There is very little published evidence of the optimal design of stewardship interventions in hospitalised children [12,13]. The data presented here suggests that PPS need to be more specifically combined with simple, cheap and easily implemented stewardship interventions.

\section{Acknowledgments}

The authors thank the GARPEC research group for their support.

\section{Authors' contributions}

MS and YH designed the study. CT, CM, MD, PD and SE collected the data. $M S, Y H, C T, C M$ and $L G$ analyzed data drafted the manuscript. All authors read and approved the final manuscript.

\section{Funding}

None.

\section{Availability of data and materials}

The datasets used and/or analysed during the current study are available from the corresponding author on reasonable request.

\section{Ethics approval and consent to participate}

Ethics approval and consent was obtained from each ethics committee of each partecipant hospital.

\section{Consent for publication}

Not applicabile.

\section{Competing interests}

None.

\section{Author details}

${ }^{1}$ Institute for Infection and Immunity, Paediatric Infectious Disease Research Group, St. George's, University of London, London, England. ${ }^{2}$ Post graduate school of Paediatrics, University of Florence, Florence, Italy. ${ }^{3}$ Department of Health Sciences, University of Florence, Anna Meyer Children's University Hospital, Viale Pieraccini 24, 50139 Florence, Italy. ${ }^{4}$ Unit of Immune and Infectious Diseases, Academic Department of Pediatrics, Children's Hospital Bambino Gesù, Rome, Italy. ${ }^{5}$ Department of Pediatrics, La Sapienza University of Rome, Rome, Italy. ${ }^{6}$ Pediatric Clinic, Department of Surgical and Biomedical Sciences, University of Perugia, Perugia, Italy.
Received: 30 June 2019 Accepted: 21 September 2019

Published online: 17 October 2019

\section{References}

1. World Health Organization (WHO). 10 facts on antimicrobial resistance. Available at: https://www.who.int/features/factfiles/antimicrobial_resistance/ en/. Last accessed 20 January 2019.

2. Society for Healthcare Epidemiology of America; Infectious Diseases Society of America; Pediatric Infectious Diseases Society. Policy statement on antimicrobial stewardship by the Society for Healthcare Epidemiology of America (SHEA), the Infectious Diseases Society of America (IDSA), and the Pediatric Infectious Diseases Society (PIDS). Infect Control Hosp Epidemiol. 2012; 33:322-7.

3. Versporten A, Bielicki J, Drapier N, et al. The worldwide antibiotic resistance and prescribing in European children (ARPEC) point prevalence survey: developing hospital-quality indicators of antibiotic prescribing for children. $J$ Antimicrob Chemother. 2016;71:1106-17.

4. De Luca M, Donà D, Montagnani C, et al. Antibiotic Prescriptions and Prophylaxis in Italian Children. Is It Time to Change? Data from the ARPEC Project. PLoS One. 2016;16(11):e0154662.

5. Ciofi Degli Atti ML. Raponi M, Tozzi AE, et al. point prevalence study of antibiotic use in a paediatric hospital in Italy. Euro Surveill. 2008;13.

6. Hufnagel $M$, Versporten A, Bielicki J, et al. High rates of prescribing antimicrobials for prophylaxis in children and neonates: results from the antibiotic resistance and prescribing in European children point prevalence survey. J Pediatric Infect Dis Soc. 2018.

7. Hsia Y, Lee RB, Versporten A, et al. Using the WHO access/watch/reserve classification to define patterns of hospital antibiotic use: analysis of pediatric point prevalence survey data from 56 countries - the first AWaRe PPS. Lancet Global Health. 2019; (in press).

8. Versporten A, Bielicki J, Drapier N, et al. The worldwide antibiotic resistance and prescribing in European children (ARPEC) point prevalence survey: developing hospital-quality indicators of antibiotic prescribing for children. $J$ Antimicrob Chemother. 2016;71:1106-17.

9. Versporten A, Sharland M, Bielicki J, et al. The antibiotic resistance and prescribing in European children project: a neonatal and pediatric antimicrobial web-based point prevalence survey in 73 hospitals worldwide. Pediatr Infect Dis J. 2013;32:e242-53.

10. CHOC. Children's. Antibiotic prophylaxis for surgery guideline. Available at: https://www.choc.org/userfiles/AntibioticProphylaxisForSurgeryGuideline.pdf.

11. Patel SJ, Saiman L. Principles and strategies of antimicrobial stewardship in the neonatal intensive care unit. Semin Perinatol. 2012;36:431-6.

12. Le Doare $\mathrm{K}$, Barker $\mathrm{Cl}$, Irwin $\mathrm{A}$, et al. Improving antibiotic prescribing for children in the resource-poor setting. Br J Clin Pharmacol. 2015;79:446-55.

13. Irwin A, Sharland M. Measuring antibiotic prescribing in hospitalised children in resource-poor countries: a systematic review. J Paediatr Child Health. 2013;49:185-92.

\section{Publisher's Note}

Springer Nature remains neutral with regard to jurisdictional claims in published maps and institutional affiliations.
Ready to submit your research? Choose BMC and benefit from:

- fast, convenient online submission

- thorough peer review by experienced researchers in your field

- rapid publication on acceptance

- support for research data, including large and complex data types

- gold Open Access which fosters wider collaboration and increased citations

- maximum visibility for your research: over $100 \mathrm{M}$ website views per year

At BMC, research is always in progress.

Learn more biomedcentral.com/submission 